\title{
ONREL
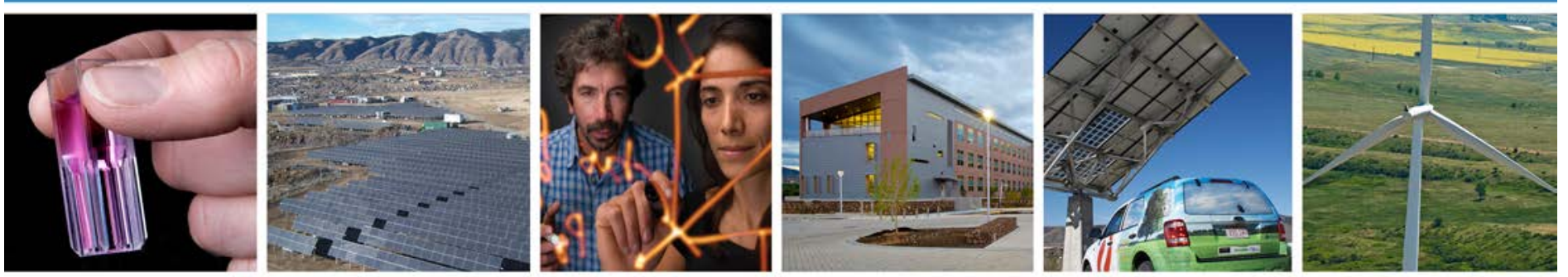

\section{Optimizing Geographic Allotment of Photovoltaic Capacity in a Distributed Generation Setting}

\section{Preprint}

B. Urquhart

National Renewable Energy Laboratory and University of California-San Diego

M. Sengupta and J. Keller

National Renewable Energy Laboratory

To be presented at the $27^{\text {th }}$ European Photovoltaic Solar Energy Conference and Exhibition

Frankfurt, Germany

September 24-28, 2012

NREL is a national laboratory of the U.S. Department of Energy, Office of Energy Efficiency \& Renewable Energy, operated by the Alliance for Sustainable Energy, LLC.

Conference Paper

NREL/CP-5500-56539

September 2012

Contract No. DE-AC36-08GO28308 


\section{NOTICE}

The submitted manuscript has been offered by an employee of the Alliance for Sustainable Energy, LLC (Alliance), a contractor of the US Government under Contract No. DE-AC36-08GO28308. Accordingly, the US Government and Alliance retain a nonexclusive royalty-free license to publish or reproduce the published form of this contribution, or allow others to do so, for US Government purposes.

This report was prepared as an account of work sponsored by an agency of the United States government. Neither the United States government nor any agency thereof, nor any of their employees, makes any warranty, express or implied, or assumes any legal liability or responsibility for the accuracy, completeness, or usefulness of any information, apparatus, product, or process disclosed, or represents that its use would not infringe privately owned rights. Reference herein to any specific commercial product, process, or service by trade name, trademark, manufacturer, or otherwise does not necessarily constitute or imply its endorsement, recommendation, or favoring by the United States government or any agency thereof. The views and opinions of authors expressed herein do not necessarily state or reflect those of the United States government or any agency thereof.

Available electronically at http://www.osti.gov/bridge

Available for a processing fee to U.S. Department of Energy and its contractors, in paper, from:

U.S. Department of Energy

Office of Scientific and Technical Information

P.O. Box 62

Oak Ridge, TN 37831-0062

phone: 865.576 .8401

fax: 865.576 .5728

email: mailto:reports@adonis.osti.gov

Available for sale to the public, in paper, from:

U.S. Department of Commerce

National Technical Information Service

5285 Port Royal Road

Springfield, VA 22161

phone: 800.553 .6847

fax: 703.605.6900

email: orders@ntis.fedworld.gov

online ordering: http://www.ntis.gov/help/ordermethods.aspx

Cover Photos: (left to right) PIX 16416, PIX 17423, PIX 16560, PIX 17613, PIX 17436, PIX 17721

Printed on paper containing at least $50 \%$ wastepaper, including $10 \%$ post consumer waste. 


\title{
OPTIMIZING GEOGRAPHIC ALLOTMENT OF PHOTOVOLTAIC CAPACITY IN A DISTRIBUTED GENERATION SETTING
}

\author{
Bryan Urquhart ${ }^{1,2}$, Manajit Sengupta, ${ }^{1}$ and Jamie Keller ${ }^{1}$ \\ ${ }^{1}$ National Renewable Energy Laboratory \\ 15013 Denver West Parkway, Golden, CO 80401, USA \\ ${ }^{2}$ University of California at San Diego \\ 9500 Gilman Drive, La Jolla, CA 92093, USA
}

\begin{abstract}
A multi-objective optimization was performed to allocate $2 \mathrm{MW}$ of photovoltaic (PV) among four candidate sites on the island of Lanai, Hawaii, such that energy was maximized and variability in the form of ramp rates was minimized. This resulted in an optimal solution set that provides a range of geographic allotment alternatives for the fixed PV capacity. Within the optimal set, a trade-off between energy produced and variability experienced was found, whereby a decrease in variability always necessitates a simultaneous decrease in energy. A design point within the optimal set was selected for study that decreased extreme ramp rates by more than $50 \%$ while decreasing annual energy generation by only $3 \%$ more than the maximum generation allocation. To quantify the allotment mix selected, a metric was developed - called the "ramp ratio"that compares ramping magnitude when all capacity is allotted to a single location to the aggregate ramping magnitude in a distributed scenario. The ramp ratio quantifies simultaneously how much smoothing a distributed scenario would experience over single site allotment and how much a single site is being underutilized for its ability to reduce aggregate variability. This paper creates a framework for use by cities and municipal utilities to reduce variability impacts while planning for high penetration of PV on the distribution grid.
\end{abstract}

Keywords: distributed generation, optimization, geographic dispersion

\section{INTRODUCTION}

The variability of solar power provides integration challenges as a primary power source on the transmission system and poses potential power quality issues for distribution networks. A known level of fluctuation in solar power output will always exist because of natural variations in the solar position. Superimposed on the known fluctuations will exist additional variability in production from installed PV that depends primarily on weather conditions that influence clouds and solar radiation at the location. It is well studied that aggregation of sites produces a smoother output of power on a per capacity basis [1-6]. These studies primarily address smoothing through geographic dispersion, and attempts have been made to mathematically model this phenomenon. On the other hand, there has been an apparent dearth of work on how to select the best geographic allocation of PV among candidate sites. This study examines the tradeoff between energy maximization and variability minimization while selecting and allocating PV generation among multiple candidate sites. In this paper, the geographic separation of the sites is small enough that we can assume that the problem we address is limited to the distribution grid. A study looking at minimizing the levelized cost of energy of a set of $12 \mathrm{PV}$ generators using daily energy as input was performed by Roy [7]. Collins and Crowther [8] performed a multi-objective optimization that maximizes daily energy while minimizing generation shortfall using hourly input data and sites distributed across the state of Virginia. The latter is similar to this study in that it evaluated the trade-off between energy maximization and variability minimization; however, the sites are far enough apart to be considered a transmission level problem. As previously mentioned, the scope of this study is restricted to geographic dispersion that can be assumed to not have the constraints imposed by balancing area coordination, line congestion, and other transmission issues.

The Maui Electric Company (MECO) owns and operates the island of Lanai's electric power system. By comparison to mainland grids, the electric power system is small. The system energy is produced by a set of diesel generators located at the main power plant, of which one or two (depending on system load requirements) provide system frequency regulation using isochronous frequency control. Currently on the island there are two large distributed generation systems in addition to the main power plant. A large central station (1.2-MW) PV installation owned and named La Ola by Castle \& Cooke is installed near the main diesel power plant that provides power to the grid through a purchase power agreement (PPA). Only recently has the La Ola PV system begun to generate power at full capacity because the PPA required that the system incorporate a battery energy storage system. This was to help mitigate ramping rates associated with the La Ola PV system. There is a combined heat and power (CHP) generator located near the end of the distribution circuit as well.

A team led by the U.S. Department of Energy's National Renewable Energy Laboratory (NREL) and MECO are working with local developers on the island of Lanai to assess the economic and technical feasibility of increasing the contribution of renewable energy sources on the island, with a stated long-term goal of reaching 100\% renewable energy as part of the Hawaii Clean Energy Initiative. For MECO, enabling the reliable installation (and determining the technical requirements associated with the reliable installation) of additional renewable resources such as PV systems onto the electric power system is one way to assist in increasing the renewable energy penetration on Lanai.

The NREL team, with input from interested PV system installers, has been working to create and evaluate viable scenarios to assess the potential amount of PV systems that can be cost-effectively installed on Lanai. In support of this, NREL has installed equipment to measure the variability of the solar resource at several locations on the island. For more than one year, NREL has been capturing 3-sec timesynchronized solar radiation data at four locations on Lanai that represent some of the possible locations for additional PV systems. Figure 1 shows the locations of the 3-sec solar irradiance data collection points, as well as some of the existing generation and load centers. This data is available to 


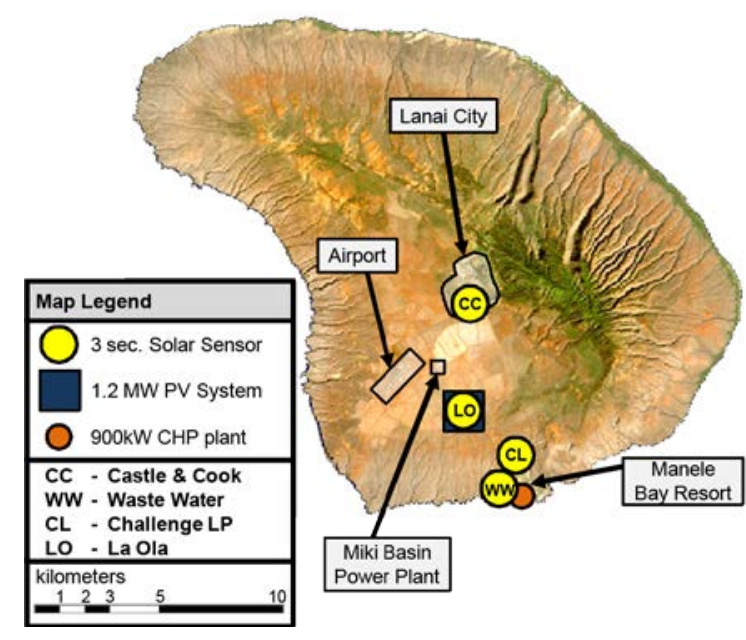

Figure 1. Map of the island of Lanai with four sensor locations indicated. The Lanai City and airport load centers are indicated, along with the La Ola PV system, the main island power plant, and a combined heat and power plant located near the coast.

help understand site resources and variability among sites; however, appropriate system simulation models and assumptions are still needed.

This paper develops a design strategy for placement of PV generation by maximizing energy produced and minimizing variability and, more specifically, power ramp rates. To do this, the planned PV output was simulated from available solar measurements for one complete year from June 2010 to May 2011. A predetermined amount of PV (e.g., 2 MW) was geographically allocated among four locations with differing amounts at each site, and the impact on energy generation and variability was quantified. To formalize this process, a multiobjective optimization scheme was employed to generate Pareto-optimality (named for the Italian economist Vilfredo Pareto) curves using several variability criteria. Paretooptimality curves provide information on the trade-offs between energy production and variability experienced. These curves are presented as a method for utilities to assess the trade-offs of maximizing energy production while minimizing system variability. The method presented provides a tool for selecting an acceptable level of ramping for an individual system.

\section{METHODOLOGY}

\subsection{Experimental Setup}

The island of Lanai is located at a latitude of $20.8^{\circ} \mathrm{N}$, where the Walker and Hadley circulations generate the northeasterly trade winds. Trade wind cumulus clouds are dominant and cause large and frequent ramps in the global horizontal irradiance (GHI) because of the highly variable nature of that cloud type (Fig 2). GHI was measured at four prospective PV deployment locations (Fig. 1, Table I) on the island using Licor LI 200 silicon pyranometers capturing data at a rate of $3 \mathrm{sec}$. The La Ola station also had regular meteorological measurements of temperature and wind data. Data was collected from April 2010 to September 2011; however, to ensure the summer half-year was not weighted more heavily in this study, only data from June 2010 to May 2011 was used.

The Castle \& Cook site is located in the center of the island, close to the mountains; the other sites are located in the southern portion of the island surrounded by much flatter terrain. Terrain-induced orographic lifting at the Castle \& Cook resulted in higher levels of cloud formation and thus a higher frequency of large ramp events at that location. The Waste Water and Challenge LP sites were close to each other and thus exhibited stronger correlation than the other two sites. Hereinafter, the four sites are referred to by their designations indicated in both Fig. 2 and Table I.

Table I. Measurement site geographic position and designation

\begin{tabular}{|c|c|c|c|c|}
\hline Site & Designation & Lat. $\left[{ }^{\circ} \mathrm{N}\right]$ & Lon. $\left[{ }^{\circ} \mathrm{W}\right]$ & Alt. [m] \\
\hline Castle \& Cook & $\mathrm{CC}$ & 20.81782 & 156.92107 & 464 \\
\hline Waste Water & WW & 20.74844 & 156.89694 & 110 \\
\hline Challenge LP & CL & 20.74102 & 156.90509 & 60 \\
\hline $\mathrm{LaOla}$ & LO & 20.76685 & 156.92291 & 381 \\
\hline
\end{tabular}

\subsection{Power Output Simulation}

Power output was simulated using irradiance to DC power and DC to AC power algorithms that are part of the PVForm performance model (version 3.3) [9, 10]. This model has been widely used since its development, including in the latest version of PVWatts [11], and has been shown to have a 5\% positive bias and RMS errors of less than 12\% [12]. The model incorporates a temperature correction for irradiance to DC conversion as well as an efficiency reduction for low irradiance levels.

The transposition model used in PVForm, based on that of Perez et al. [13], to convert the horizontal irradiance measurements to plane-of-array (POA) irradiance was not used here. The goal of this study was to develop a methodology to optimize the benefits of geographic smoothing and did not aim to achieve high accuracy in the exact energy produced or ramp rates experienced. Both the energy output and ramp rates would increase if GHI was transposed to POA. Importantly, however, the trends would remain the same; that is the basis for the results presented here. An additional consideration is that the latitude was low; therefore, the tilt would be close to horizontal, so there was less error in making the horizontal simplification than would occur at higher latitudes.

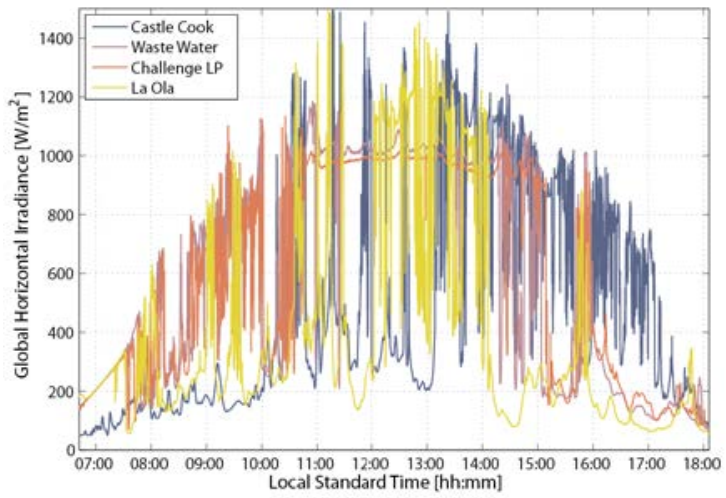

Figure 2. GHI on June 20, 2011, showing typical large, cumulusinduced fluctuations on the island of Lanai, Hawaii.

It should be mentioned that direct performance model conversion of irradiance to power output is somewhat misleading. Large PV plants exhibit intra-plant smoothing similar to a low pass filter $[14,15]$. Both Marcos et al. [14] and Lave et al. [16] developed Fourier and wavelet-based methods, respectively, to smooth modeled intra-plant power output so that it better matches observed output. Intra-plant smoothing was not considered here. The aggregate capacity of 
the four simulated sites was $2 \mathrm{MW}$, which is relatively small in total area, and it was assumed that direct use of a PV performance model does not impact the utility of the results presented.

2.3 Multi-Objective Optimization: Maximizing Energy Generation While Minimizing Ramp Rate

Using a predetermined installed capacity of PV to be allocated among the four candidate sites, an optimization was performed to determine which weighting ( $\%$ of total) allocation at each site would provide the most energy while also having the lowest variability. To maximize only energy, one would simply place $100 \%$ capacity in the sunniest location. This would not provide the smoothest output in general, and if variability was a concern, utilities could take advantage of geographic dispersion and place some capacity in less sunny locations. This would result in a potential reduction in total energy produced but would also lead to reduction in the variability. To avoid defining a subjective cost penalty for each parameter being optimized, as is done in standard linear programming, the energy and variability criteria were treated as distinct objectives. This multiobjective optimization problem does not have a single unique solution, but instead has a range of solutions, known as the Pareto-optimal set, which describe a range of non-inferior alternatives for maximizing energy while minimizing variability. Arbitrarily selecting how to allocate capacity may reduce energy while not decreasing the variability significantly. For the Pareto-optimal set, the maximum energy output is achieved for a given level of variability.

Figure 3 shows an example of the Pareto-optimal set for minimizing the $99^{\text {th }}$ percentile of ramp rates while maximizing energy. Moving along this curve (also called the Paretooptimal frontier), one must trade energy generated for a reduction in variability, characterized here by ramp rates. At any point, in the Pareto-inferior region one can increase energy or decrease ramp rate without sacrificing the other, and corresponds to an inefficient selection of geographic allocation. Points along the curve are Pareto-efficient in that, to change one quantity, one must sacrifice the other. A system designer can then select the maximum level of variability a given electrical system can handle, and the corresponding point on the Pareto-optimal frontier will yield the geographic allocation for maximum energy production.

It should be noted that although we used ramp rates exclusively to quantify variability in this work, other metrics - such as ramp size, ramp frequency, or generation shortfall (if load information is available) — can be used and will be the subject of future study. Ramp rate $r_{j}(t, \Delta t)$ at a time $t$ for an interval $\Delta \mathrm{t}$ is defined as

$r_{j}(t, \Delta t)=\frac{p_{j}(t+\Delta t)-p_{j}(t)}{\Delta t}$

where $p_{j}(t)$ is the power output at site $j$. The probability density of ramp rates over the one year studied (June 2010 to May 2011) for LO is given in Fig. 4 for different $\Delta t$. This shows the usual result that ramp rates are largest for the smallest $\Delta t$; thus, for the optimization, only ramp rates at the 3 -sec data capture rate are used. Minimization of 3-sec ramp rates ensures that ramp rates for all other $\Delta t$ will always be smaller. No ramp rates were excluded in any computation step, even if very small, to ensure illumination of the true probability of occurrence of large ramp events in all statistical results. The cumulative distribution function indicated that

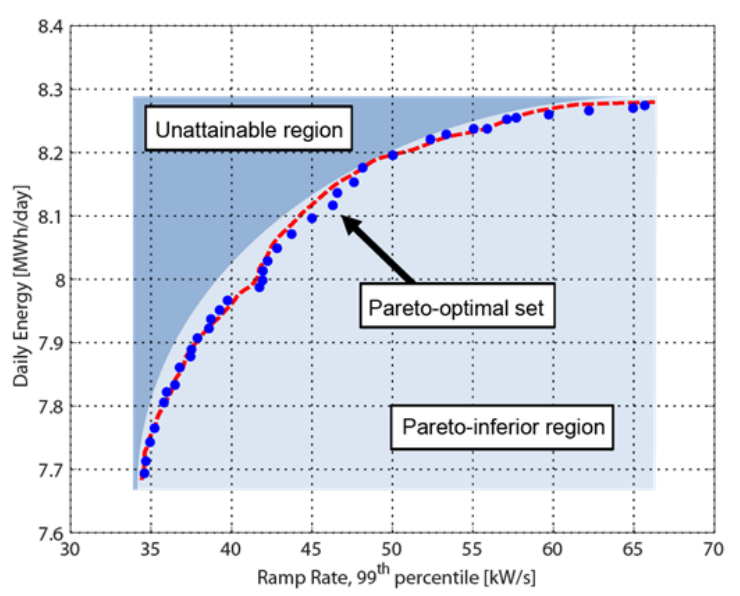

Figure 3. The Pareto-optimal set for maximizing energy while minimizing the $99^{\text {th }}$ percentile of ramp rates. The curve is shown to divide two regions: an unattainable set of energy, ramp rate combinations; and an inferior set where individually either energy can be increased or ramp rates decreased without compromising the other.

$99 \%$ of 3 -sec ramp rates were below $4 \%$ of capacity, and $99.9 \%$ of ramp rates were below $10 \%$ of capacity for the La Ola site.

The multi-objective optimization employs a genetic algorithm using a tournament selection scheme described in [17]. The genetic algorithm tries many successive combinations of weights, pushing the Pareto frontier outward until no other variation of weight allocation can extend the curve farther into the optimal territory. During this process, the solution set in each successive iteration is combined (crossover) and "mutated," and less fit alternatives are removed in an emulation of genetic evolution. The objective functions to be minimized are:

$f(\boldsymbol{w})=-\sum_{i} w_{j} p_{j}\left(t_{i}\right) \Delta t$

$g_{n}(\boldsymbol{w})=P_{n}\left(\left|w_{j} r_{j}\left(t_{i}, \Delta t\right)\right|\right)$,

where $w_{j}$ is the component of weight vector $\boldsymbol{w}$ corresponding to the geographic allocation for site $j$, and $P_{n}(\cdot)$ is the $n^{\text {th }}$ percentile of the argument. Summation on $j$ is implied for both equations (2) and (3). Equation (2) is the negative of total energy output by the aggregate system for configuration $\boldsymbol{w}$, and equation (3) is $n^{\text {th }}$ percentile of system aggregate ramp rate computed for the entire set of $i$ ramp rates (i.e., ramp rates from the entire year data set). In equation (3), only the magnitude of the elements in the set are considered, denoted by the vertical bars. The constraints on the optimization are

$\sum_{j} w_{j}=1, w_{j} \in[0,1]$,

which requires that all weights sum to unity and that any given site can be weighted only from $0 \%$ to $100 \%$. The notation used above contains a subtlety for computational purposes where both power and ramp rates used in equations (2) and (3) for individual sites are scaled so that each site is initially at $2 \mathrm{MW}$ of capacity (8 MW total) so that when multiplied by the weights $\boldsymbol{w}$ the aggregate capacity is the desired $2 \mathrm{MW}$. This implementation and notation must be changed if intra-plant smoothing is considered. Power output and thus ramp rates are no longer independent of assigned capacity, and the power time series and thus ramp rates must be adjusted by means of a smoothing filter $[14,16]$. 


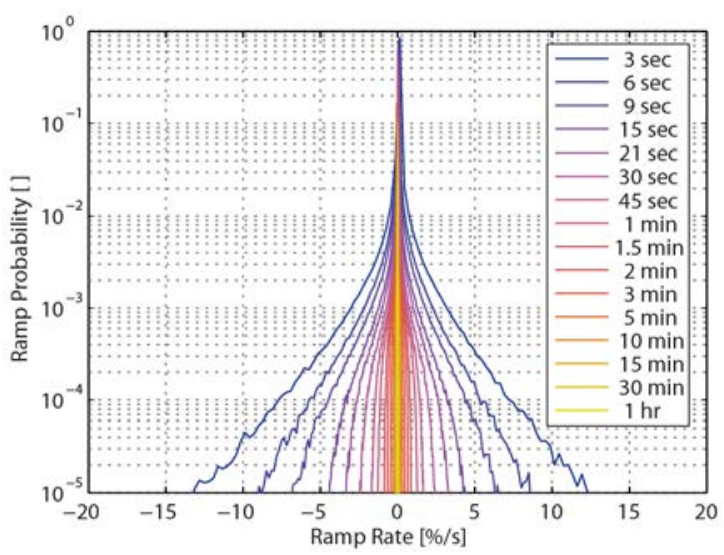

Figure 4. Probability distribution of ramp rates for several time steps at the La Ola site. Ramp rates are shown as a percentage of total power output capacity. Small or negligible ramp rates were included; thus, the curves indicate true probability of events.

\section{RESULTS}

To assess the trade-off between ramp rates and energy production, multiple ramp rate percentiles were used as minimization criteria. Figure 5 (a) shows the $97^{\text {th }}, 98^{\text {th }}, 99^{\text {th }}$, and $99.5^{\text {th }}$ percentile Pareto-optimal curves, along with an interpolated color swath to indicate the spread in site weighting. The darker color indicates that the standard deviation of the four weight values was low. The upper bound of $8.26 \mathrm{MWh}$ was the maximum production possible for a 2MW plant during the one year studied; thus, the allocation was $100 \%$ at the CL site, with corresponding high standard deviation of the four weights. The near verticality of the $97^{\text {th }}$ percentile showed that by changing the weights, not much improvement was made in reducing the ramp rates. At higher percentiles, such as 99.5, significant gains could be seen by adjusting the weights, and ramp rates dropped by nearly $40 \%$ for a $3 \%$ reduction in energy generated.

Taking a more expanded view of the high end of ramp rate space, Fig. 5 (b) shows ramp rate percentiles up to the $99.999^{\text {th }}$ percentile. The space between this percentile and the $100^{\text {th }}$ percentile is spanned by only 43 data points. More than one year of data is needed to provide statistical context for percentiles beyond the "five nines" level, and this was the maximum percentile considered here. At $99.999^{\text {th }}$ percentile, a more than $50 \%$ reduction in the magnitude of extreme ramps can be achieved with only a 3\% drop in energy produced when site allocations are properly selected. In Fig. 5 (b), the color shading indicates that for lower ramp rates, geographic allocation was more evenly distributed. As shown, for each energy level, the site weightings appeared somewhat independent of ramp rate percentile. This was a positive result because it implied that geographic dispersion lowers ramp rates at every level. The multi-objective optimization was run to simultaneously minimize two ramp rate percentiles (e.g., $99^{\text {th }}$ and $99.99^{\text {th }}$ percentile) while maximizing energy, and the result indicated that the geographic allocation used to reduce ramp rates in one percentile was beneficial to the other. This means that optimal solutions at low ramp rates have similar site allocations, a fact not clear from looking at the standard deviation of weights alone. The three-dimensional plot is not shown because perspective effects make it difficult to interpret on the written page. The site weighting and ramp rates for a selection of points in Fig. 5 (b) are given in Table II
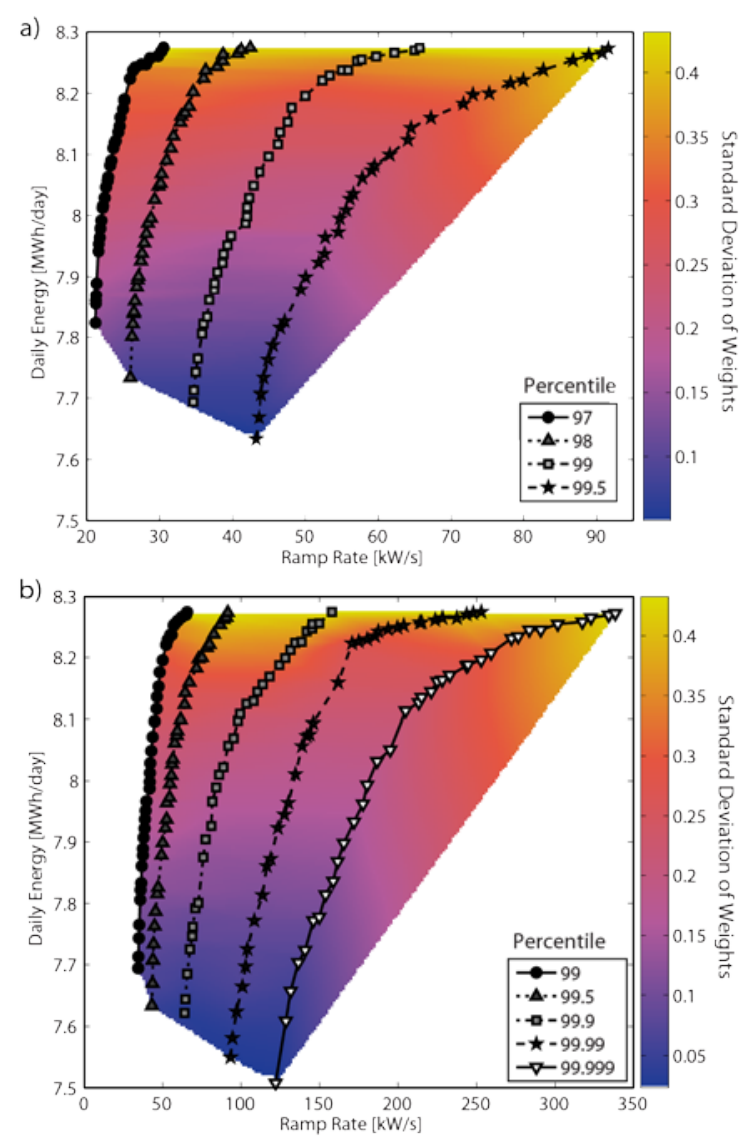

Figure 5. Pareto-optimal sets for (a) the $97^{\text {th }}, 98^{\text {th }}, 99^{\text {th }}$, and $99.5^{\text {th }}$ percentile and (b) the $99^{\text {th }}, 99.5^{\text {th }}, 99.9^{\text {th }}, 99.99^{\text {th }}$, and $99.999^{\text {th }}$ percentile. The standard deviation of the geographic allocation (as a fraction of the total), is shown as a color swath where darker color indicates low deviation and lighter color indicates a single site that has a majority allocation.

as a function of energy and ramp rate percentile.

A system designer is bound by economic constraints and cannot simply minimize ramp rate while disregarding a potentially significant drop in energy output. The exact requirements are of course system dependent, but here an example case was selected where energy was decreased from only the $8.26-\mathrm{MWh}$ maximum to an $8-\mathrm{MWh}$ design point (OPT). The site weights for this case are given in Table III, and the resulting ramp rate percentiles are given in Table IV. For comparison, Table IV also includes the ramp rates at different percentiles when all $2 \mathrm{MW}$ was allocated to each site separately. As expected, the ramp rates of OPT were smaller at all percentiles, but the important result is that energy was not significantly reduced from the maximum achievable level. In fact, it was significantly higher than could be achieved with $100 \%$ allocation at either CC or LO. Comparing OPT to the equal allocation case (EQ) shows that one can reduce ramps over OPT, but energy dropped by nearly $9 \%$ above the maximum and $6 \%$ above OPT. In the limit of zero correlation of ramp rates between sites, the EQ scenario would be the best geographic allocation for ramp rate minimization. Because there was a small degree of correlation, even at short time scales, a multi-objective optimization minimizing the $99^{\text {th }}$ and $99.99^{\text {th }}$ percentile and ignoring energy output yielded the lowest overall ramp rates (MIN, Table IV). The MIN results marginally improved both ramp rate reduction and energy production over EQ. 
Table II. Site allocation weight values on the Pareto-optimality curves for minimization of the $99^{\text {th }}, 99.9^{\text {th }}$ and $99.99^{\text {th }}$ percentile of ramp rates, shown as a function of aggregate daily energy produced. Aggregate system ramp rates are also shown.

\begin{tabular}{|c|c|c|c|c|c|c|c|c|c|c|c|c|c|c|c|}
\hline \multirow{3}{*}{$\begin{array}{c}\text { Energy } \\
{[\mathrm{MWh} / \text { day }]}\end{array}$} & \multicolumn{5}{|c|}{$99^{\text {th }}$ pctile } & \multicolumn{5}{|c|}{$99.9^{\text {th }}$ pctile } & \multicolumn{5}{|c|}{$99.99^{\text {th }}$ pctile } \\
\hline & \multicolumn{4}{|c|}{$\begin{array}{l}\text { Weights } \\
{[\%]}\end{array}$} & \multirow{2}{*}{$\begin{array}{l}\text { Ramp } \\
\text { Rate } \\
{[\mathrm{kW} / \mathrm{s}]}\end{array}$} & \multicolumn{4}{|c|}{$\begin{array}{c}\text { Weights } \\
{[\%]}\end{array}$} & \multirow{2}{*}{$\begin{array}{l}\text { Ramp } \\
\text { Rate } \\
{[\mathrm{kW} / \mathrm{s}]}\end{array}$} & \multicolumn{4}{|c|}{$\begin{array}{c}\text { Weights } \\
{[\%]}\end{array}$} & \multirow[t]{2}{*}{$\begin{array}{c}\text { Ramp Rate } \\
{[\mathrm{kW} / \mathrm{s}]}\end{array}$} \\
\hline & $\mathrm{CC}$ & WW & $\mathrm{CL}$ & LO & & $\mathrm{CC}$ & WW & $\mathrm{CL}$ & LO & & $\mathrm{CC}$ & WW & $\mathrm{CL}$ & LO & \\
\hline 7.60 & - & - & - & - & - & 21 & 27 & 30 & 22 & 64 & 20 & 24 & 32 & 24 & 96 \\
\hline 7.70 & 17 & 26 & 36 & 21 & 35 & 20 & 28 & 34 & 18 & 67 & 18 & 25 & 37 & 20 & 103 \\
\hline 7.80 & 13 & 27 & 43 & 17 & 36 & 16 & 27 & 42 & 15 & 73 & 14 & 29 & 41 & 16 & 112 \\
\hline 8.20 & 2 & 19 & 78 & 1 & 52 & 3 & 15 & 81 & 1 & 128 & 2 & 32 & 65 & 1 & 168 \\
\hline 8.26 & 0 & 0 & 100 & 0 & 66 & 0 & 0 & 100 & 0 & 158 & 0 & 0 & 100 & 0 & 253 \\
\hline
\end{tabular}

Legend: Castle Cook (CC), Waste Water (WW), Challenge LP (CL), La Ola (LO)

To quantify the level of geographic smoothing of ramp rates, a new metric termed the "ramp ratio" was introduced. The ramp ratio $R R_{j}^{n}$ for the $j^{\text {th }}$ site at the $n^{\text {th }}$ percentile is defined as

$R_{j}^{n}=\frac{P_{n}\left(\left|r_{j}\left(t_{i}, \Delta t\right)\right|\right)}{P_{n}\left(\left|w_{j} r_{j}\left(t_{i}, \Delta t\right)\right|\right)}$,

where summation over $\mathrm{j}$ is implied by repeated indices. Effectively, ramp ratio compares ramping magnitude when all capacity is allotted to a single location to the aggregate ramping magnitude in a distributed scenario with allocation weights $\mathrm{w}_{\mathrm{j}}$. For a time period with no variability, such as on a clear day, and assuming all sites are proximal enough that the solar resource is nearly the same, the ramp rates of an individual site are a result of changes in solar geometry. In this case, the ramp ratio had a value close to one. This corresponded to a high correlation between sites because they increased and decreased in unison with the movement of the sun. When there was variability because of the presence of clouds, the correlation between sites began to decrease at short time scales. This resulted in compensating ramps when the plants were distributed, which ultimately resulted in smoothing. This characteristic showed up as ramp ratios that were greater than one, indicating that the total system output was smoother on a per capacity basis than the $j^{\text {th }}$ constituent site. The value of the ramp ratio quantified the level of increased geographic smoothing, e.g. $R R_{j}^{99}=2$ indicates that the aggregate system output was two times smoother than site

Table III. Site geographic allocation percentage for seven scenarios: CC, WW, CL, and LO allocate all capacity at a single site; OPT uses weighting for the 8-MWh design point; EQ equally weights each site; MIN weighting mix shows results from minimization of the $99^{\text {th }}$ and $99.99^{\text {th }}$ percentile ramp rates; and LAN is a Lanai case study.

\begin{tabular}{lrrrr}
\hline & \multicolumn{3}{c}{ Site Geographic Allocation $[\%]$} \\
\cline { 2 - 4 } Site & CC & WW & CL & \multicolumn{1}{c}{ LO } \\
\cline { 5 - 6 } \cline { 5 - 6 } CC & 100 & 0 & 0 & 0 \\
WW & 0 & 100 & 0 & 0 \\
CL & 0 & 0 & 100 & 0 \\
LO & 0 & 0 & 0 & 100 \\
OPT & 9 & 30 & 53 & 8 \\
EQ & 25 & 25 & 25 & 25 \\
MIN & 22 & 26 & 26 & 26 \\
LAN & 13 & 13 & 13 & 61 \\
\hline
\end{tabular}

Legend: Castle Cook (CC), Waste Water (WW), Challenge LP (CL), La Ola (LO), Optimum Allocation (OPT), Equal Allocation (EQ), Minimum Ramp Allocation (MIN), Lanai case study (LAN) j at the $99^{\text {th }}$ percentile of ramp rates. It may so happen that the ramp ratio was less than one. This would imply that a particular site was actually less variable than the aggregate. In this case, the weights allotted to the sites were obviously not optimal, with greater weights having been allotted to sites with high variability at the expense of low variability sites. In such a scenario, reallocation of capacity would be beneficial.

Several examples of the ramp ratio $\mathrm{RR}_{\mathrm{j}}^{99}$ are given in Figure 6 for different allocation scenarios across different months. The EQ case (Fig. 6 (a)) shows that smoothing was not uniform for all months and tended to be higher during the summer. Figure 6 (b) shows the OPT case. The island of Lanai currently has 1.2 MW of PV installed at the La Ola site, so it is of practical interest to look into the scenario where the remainder of the $2 \mathrm{MW}$ is distributed equally among other sites. Figure 6 (c) shows the Lanai case study scenario (LAN, Table III). Overall, in comparison to Fig. 6 (b) and Fig. 6 (c), EQ had the highest and most consistent $\mathrm{RR}_{\mathrm{j}}^{99}$, which was to be expected for nearly uncorrelated signals. During the winter half-year, WW and CL, the sites near each other, had lower $\mathrm{RR}_{\mathrm{j}}^{99}$ in EQ and thus were less variable than CC and LO. This is one reason why the OPT case weighted WW and CL more heavily than the other sites. Figure 6 (b) reflects this increase in weighting because the ramp ratios of $\mathrm{WW}$ and CL were more uniform across the year. These two sites also produced more energy on average and therefore had a higher weighting

Table IV. Energy production and ramp rates at the $99^{\text {th }}, 99.9^{\text {th }}$, $99.99^{\text {th }}$, and $99.999^{\text {th }}$ percentile for seven weighting scenarios: CC, WW, CL, and LO show results for single site allocation at each respective site; OPT shows results for the 8-MWh design point; the EQ case uses $25 \%$ weight at each site; MIN uses a site mix to minimize ramp rates irrespective of energy generation; and LAN is a Lanai case study scenario.

\begin{tabular}{|c|c|c|c|c|c|}
\hline \multirow[b]{2}{*}{ Site } & \multirow{2}{*}{$\begin{array}{c}\text { Energy } \\
{[\mathrm{MWh} / \text { day }]}\end{array}$} & \multicolumn{4}{|c|}{$\begin{array}{c}\text { Ramp Rate } \\
{[\mathrm{kW} / \mathrm{s}]}\end{array}$} \\
\hline & & $99^{\text {th }}$ pct & $\begin{array}{c}99.9^{\text {th }} \\
\text { pct }\end{array}$ & $\begin{array}{l}99.99^{\text {th }} \\
\text { pet }\end{array}$ & $\begin{array}{c}99.999^{\text {th }} \\
\text { pct }\end{array}$ \\
\hline $\mathrm{CC}$ & 6.93 & 86 & 198 & 314 & 401 \\
\hline WW & 8.19 & 71 & 166 & 266 & 362 \\
\hline CL & 8.27 & 66 & 158 & 253 & 339 \\
\hline LO & 6.72 & 78 & 177 & 276 & 358 \\
\hline OPT & 8.00 & 41 & 89 & 140 & 189 \\
\hline EQ & 7.53 & 35 & 65 & 94 & 127 \\
\hline MIN & 7.55 & 35 & 64 & 93 & 126 \\
\hline LAN & 7.13 & 49 & 111 & 173 & 225 \\
\hline
\end{tabular}

Legend: Castle Cook (CC), Waste Water (WW), Challenge LP (CL), La Ola (LO), Optimum Allocation (OPT), Equal Allocation (EQ), Minimum Ramp Allocation (MIN), Lanai case study (LAN) 

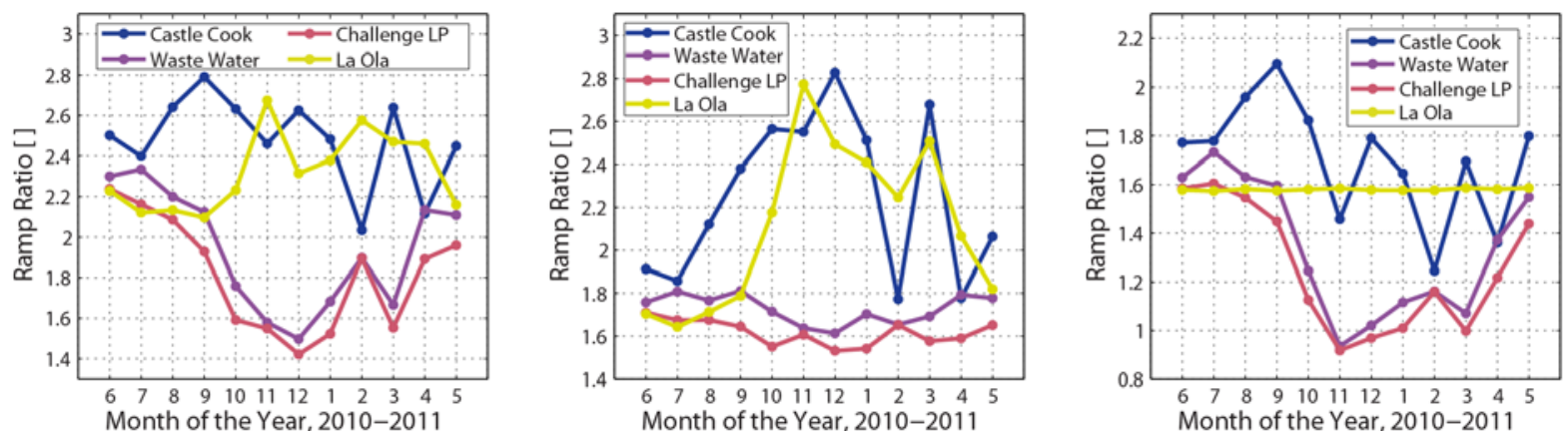

Figure 6. Monthly ramp ratios at the $99^{\text {th }}$ percentile for (a) the equal allocation scenario EQ, (b) the 8-MWh design point scenario OPT, and (c) a Lanai case study LAN reflecting currently installed capacity at La Ola.

in the optimization. The energy generation and ramp rates of the LAN scenario were well within the Pareto-inferior region (Table IV). Fig. 6 (c) shows the ramp ratio was lower than OPT or EQ, and in fact dipped below one in November. The ramp ratios below one means these sites were underutilized in this scenario for their ability to decrease ramping during the winter.

The previous discussion for ramp ratio used the $99^{\text {th }}$ percentile as the baseline for comparison of monthly and inter-site variability. Use of a different percentile, specifically higher percentiles, provided a different quantification for understanding variability. Extremely large ramp ratescaused by the passage of an individual cumulus cloud with the direct solar beam along with greater than average cloud enhancement just beyond the leading or trailing edge-are infrequent and typically affect only a single site. These extreme ramp events at one site will generally not have any correlation to other locations. Aggregation of sites under these conditions will therefore invariably result in smoothing, which is reflected by higher ramp ratios. The larger the ramp event (and thus higher percentile), the larger the inter-site decorrelation; therefore, the ramp ratio tends to increase as percentile considered increases.

The probability distributions (PDFs) of large ramp events are shown in Fig. 7. Reviewing the design point case OPT, the ramp rates were reduced significantly over all four single site allocation scenarios. The EQ case had the lowest extreme ramp rates by a significant margin. The LAN case reduced the variability over the single site cases, but ramping was larger than OPT by almost an order of magnitude toward the upper tail of the distribution, and it generated more than $10 \%$ less energy per annum. The juxtaposition of the OPT case to that of LAN underscores the benefit of designing a system for optimal use of the available solar resource while taking maximum advantage of its spatial de-correlation at the time scale considered.

\section{CONCLUSIONS}

It is well known that geographic dispersion provides a smoother overall output on a per capacity basis than centralized generation, but the optimal allocation to generate the most energy output while minimizing the variability has not been widely studied. A multi-objective optimization scheme was employed to investigate if variability can be significantly minimized while maintaining high levels of energy production. It was shown that an optimal set of alternative geographic allocation exists to maximize energy production and minimize variability. With proper geographic allotment of generation, ramp rates were reduced by $50 \%$; whereas energy was reduced by only $3 \%$ over the maximum production case. A useful result for system designers is that the exact level of variability can be tuned to an acceptable level, with the understanding that if the solution is optimal, then energy generation must be compromised as indicated by the shape of the Pareto-optimal set.

In addition to showing that there exists a clear energyvariability trade-off, a new metric was introduced, termed the ramp ratio, which can be used to assess multisite geographic allocations and their effect on variability. This ratio showed simultaneously how much smoothing the aggregate system experiences over any individual site, and also if any particular site has significantly less variability per unit capacity than the other sites in the mix. It is important to note that the ramp ratio was developed to assess optimality of capacity allocation among multiple sites; therefore, looking at a single site's ramp ratio in isolation does not provide a complete set of information. The ramp ratio can be extended into a curve in the temporal dimension by segmenting the input data set (as done in this work) or into the magnitude dimension by looking at different percentiles of variability.

The methods applied here will be extended to other variability criteria beyond ramp rates in future work. The metrics of energy and ramp rate are directly derived from resource data, but for power systems application at the distribution level, voltage fluctuations and cost will be the key metrics optimized in the kind of analysis presented here. Additional future work will involve implementing this multiobjective optimization with a feeder simulation where

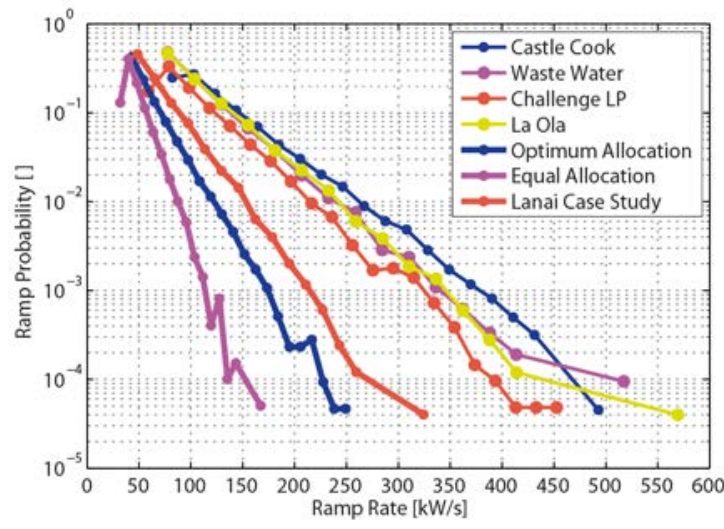

Figure 7. Probability distribution of ramp rates over the $99^{\text {th }}$ percentile. The sign of the ramp was not considered. The distribution was scaled such that the probability of all ramps over the $99^{\text {th }}$ percentile summed to unity. Allocating all capacity to four sites separately is shown (thin lines), along with three multisite allocation cases (thick lines). 
economic benefit is maximized and voltage variations are minimized. In this study, no restriction was placed on the quanta of generation installed at any given site, and no site was given a minimum threshold to be considered active. For a realistic feeder simulation, generation siting will be practically limited by space constraints and by operations and maintenance constraints. These elements need to be included so their impact on the Pareto-optimal set of alternatives can be quantified.

This paper in effect creates a framework that can be used by cities and municipal utilities that would like to see a high penetration of PV and would be interested in reducing the variability impacts on the distribution grid. The development that energy and variability have a clear trade-off, and that this trade-off can be optimized for unique scenarios, offers an opportunity to communities and utilities to leverage this to their advantage. The methods presented can be incorporated into power system design and simulation tools so that designers of future PV systems can assess geographical allocations that provide the maximum benefit. This work offers only a glimpse of what can be achieved in maximizing the utility of the solar resource through optimized geographic allotment.

It is important to note that such studies are valuable before deployment of PV; however, to conduct such studies, there is a need to collect high-resolution time-synchronized solar radiation data sets for a reasonably extended period of time. Such deployments are relatively inexpensive but can provide a high level of benefit when planning high level penetration of $\mathrm{PV}$ on the distribution grid.

\section{ACKNOWLEDGEMENT}

This work was supported by the U.S. Department of Energy under Contract No. DE-AC36-08-GO28308 with the National Renewable Energy Laboratory.

\section{REFERENCES}

[1] Murata, A; Otani, K. “An Analysis of Time-Dependent Spatial Distribution of Output Power From Very Many PV Power Systems Installed on a Nationwide Scale in Japan." Solar Energy Materials and Solar Cells (47) 1997; pp. 197-202. DOI: 10.1016/S0927-0248(97)000408.

[2] Otani, K; Minowa, J.; Kurokawa, K. "Study on a Real Solar Irradiance for Analyzing Areally-Totalized PV Systems." Solar Energy Materials and Solar Cells (47) 1997; pp. 281-288. DOI: 10.1016/S0927-0248(97)000500.

[3] Wiemken, E.; Beyer, H.G.; Heydenreich, W.; Kiefer, K. "Power Characteristics of PV Ensembles: Experiences From the Combined Power Production of 100 GridConnected PV Systems Distributed Over the Area of Germany." Solar Energy (70:6) 2001; pp. 513-518. DOI: 10.1016/S0038-092X(00)00146-8.
[4] Lave, M.; Stein, J.; Ellis, A; Hansen, C.; Nakashima, E.; Miyamoto, Y. Ota City: Characaterizing Output Variability From 553 Homes With Residential PV Systems on a Distribution Feeder. SAND2011-9011. Albuquerque, NM: Sandia National Laboratories, 2011.

[5] Curtright, A.E.; Apt, J. "The Character of Power Output From Utility-Scale Photovoltaic Systems." Progress in Photovoltaics (16) 2008; pp. 241-247. DOI: 10.1002/pip.786.

[6] Marcos, J.; Marroyo, L.; Lorenzo, E.; Garcia, M. "Smoothing of PV Power Fluctuations by Geographical Dispersion." Progress in Photovoltaics: Research and Applications (20) 2012; pp. 226-237. DOI: 10.1002/pip.1127.

[7] Roy, S. "Optimal Planning for Utility Generation by Photovoltaic Sources Spread Across Multiple Sites." IEEE Transactions on Energy Conversion (21:1) 2006; pp. 181-186.

[8] Collins, R.D.; Crowther, K.G. "Systems-Based Modeling of Generation Variability Under Alternate Geographic Configurations of Photovoltaic (PV) Installations in Virginia." Energy Policy (39) 2011; pp. 6262-6270.

[9] Menicucci, D.F.; Fernandez, J.P. User's Manual for PVFORM: A Photovoltaic Simulation Program for StandAlone and Grid-Interactive Applications. SAND85-0376 . UC-276. Albuquerque, NM: Sandia National Laboratories: 1988.

[10] Menicucci, D.F. "Photovoltaic Array Performance Simulation Models. Solar Cells (18) 1986; pp. 383-392.

[11] Marion, B.; Anderberg, M.; George, R.; Gray-Hann, P.; Heimiller, D. "PVWATTS Version 2-Enhanced Spatial Resolution for Calculating Grid-Connected PV Performance." NREL/CP-560-30941. Golden, CO: National Renewable Energy Laboratory: 2001.

[12] Perez, R.; Doty, J.; Baily, B.; Stewart, R. "Experimental Evaluation of a Photovoltaic Simulation Program." Solar Energy (52:4) 1994; pp. 359-365.

[13] Perez, R.; Seals, R. "A New Simplified Version of the Perez Diffuse Irradiance Model for Tilted Surfaces." Solar Energy 39(3) 1987; pp. 221-231.

[14] Marcos, J.; Marroyo, L.; Lorenzo, E.; Alvira, D.; Izco, E. "Power Output Fluctuations in Large-Scale PV Plants: One-Year Observations With One-Second Resolution and a Derived Analytic Model." Progress in Photovoltaics: Research and Applications (19) 2011; pp. 218-227. DOI: 10.1002/pip.1016.

[15] Marcos, J.; Marroyo, L.; Lorenzo, E.; Alvira, D.; Izco, E. "From Irradiance to Output Power Fluctuations: The PV Plant as a Low Pass Filter." Progress in Photovoltaics: Research and Applications (19) 2011; pp. 505-510. DOI: 10.1002/pip. 1063.

[16] Lave, M.; Kleissl, J.; Arias-Castro, E. "High-Frequency Irradiance Fluctuations and Geographic Smoothing." Solar Energy 2011; in press. DOI:10.1016/j.solener.2011.06.031.

[17] Kalyanmoy, D. Multi-Objective Optimization Using Evolutionary Algorithms. Chichester, England: Wiley, 2011. 